\title{
Targeted Mutation of the Gene for Cellular Glutathione Peroxidase (Gpx1) Increases Noise-Induced Hearing Loss in Mice
}

\author{
Kevin K. Ohlemiller, ${ }^{1}$ Sandra L. McFadden, ${ }^{2}$ Da-Lian Ding, ${ }^{2}$ Patricia M. Lear, ${ }^{1}$ \\ AND YE-SHIH $\mathrm{HO}^{3}$ \\ ${ }^{1}$ Fay and Carl Simons Center for the Biology of H earing and Deafness, Central In stitute for the Deaf, St. L ou is, M 0 63110, USA \\ ${ }^{2}$ Center for H earing and Deafness, State University of New York, Buffalo, NY 14214, USA \\ IInstitute of Chemical Toxicology, Wayne State University, Detroit, M I 48201, USA
}

Received: 17 April 2000; Accepted: 16 August 2000; Online publication: 17 October 2000

\begin{abstract}
Reactive oxygen species (ROS) and oxidative stress have been implicated in cochlear injury following loud noise and ototoxins. Genetic mutations that impair antioxidant defenses would be expected to increase cochlear injury following acute insults and to contribute to cumulative injury that presents as age-related hearing loss. We examined whether genetically based deficiency of cellular glutathione peroxidase, a major antioxidant enzyme, increases noise-induced hearing loss in mice. Two-month-old "knockout" mice with a targeted inactivating mutation of the gene coding for glutathione peroxidase ( $G p \times 1)$ and wild type controls were exposed to broadband noise for one hour at 110 $\mathrm{dB}$ SPL. Auditory brainstem response (ABR) thresholds at test frequencies ranging from 5 to $40 \mathrm{kHz}$ were obtained two and four weeks after exposure to determine the stable permanent component of the hearing loss. Depending on test frequency, (compared with controls) Gpxl knockout mice showed up to $16 \mathrm{~dB}$ higher $A B R$ thresholdsprior to noise exposure, and up to $15 \mathrm{~dB}$ greater noise-induced hearing loss, compared with normal control. Within the cochlear base, there was also a significant contribution of the knockout to inner and outer hair cell loss, as well as nerve fiber loss. O ur results support a link between genetic impairment of antioxidant defenses, vulnerability of the
\end{abstract}

Correspondence to: Dr. Kevin K. Ohlemiller $\bullet$ Research Department Central Institute for the Deaf $\bullet 818 \mathrm{~S}$. Euclid $\bullet$ St. Louis, MO 63110. Telephone: (314) 977-0279; fax: (314) 977-0030; email: kohlemiller@cid.wustl.edu cochlea injury, and cochlear degeneration. Such impairment producescharacteristics expected of some mutations associated with age-related hearing loss and offers one possible mechanism for their action.

Keywords: cochlea, hair cells, reactive oxygen species, free radical, knockout, antioxidant

\section{INTRODUCTION}

Mounting evidence implicates reactive oxygen species (ROS) in cochlear injury. Increased production of ROS has been demonstrated following cochlear ischemia (Ohlemiller and Dugan 1999), application of ototoxic compounds (Clerici et al. 1996; H irose et al. 1997; Kopke et al. 1997), and exposure to loud noise (Yamane et al. 1995; O hlemiller et al. 1999b). Acute impairment of antioxidant defenses promotes cochlear injury caused by these agents ( $\mathrm{H}$ offman et al. 1988; Yamasoba et al. 1998; $\mathrm{Hu}$ et al. 1999) and, conversely, temporarily bolstering these defenses provides partial protection (Seidman and Quirk 1991; Seidman et al. 1991; Seidman and Shivapuja 1993; Garetz et al. 1994a; Garetz et al. 1994b; Hu et al. 1997). Impairment of antioxidant defenses presumably leads to increases in stress-related levels of peroxides, as well as superoxide and hydroxyl radicals, with resulting amplification of injury to lipids, proteins, and DNA of sensory cells (H alliwell 1992; Gotz et al. 1994; Evans and Halliwell 1999). Insights into the role of oxidative stress in the cochlea led to the first testable models of "metabolic" cochlear injury and have provided some of the first therapeutic approaches to preventing it. 
Chronic oxidative stress may underlie some sensorineural age-related hearing loss (ARHL) by simple application of the free radical theory of aging ( $\mathrm{Har}$ man and Piette 1960) to the cochlea. Since oxidative injury is (or should be) remediable, and since ARH L is by far the most common form of hearing loss, identifying mechanisms that may link cumulative oxidative injuryand ARHL promisessignificant benefits. Testing this model solely by experimentally inducing a known and realistic amount of oxidative stress for an adequate period is impractical. Gene "knockout" techniques, however, have made it possible to create a state of chronic stress by impairing the function of genes that impact cellular antioxidant defenses. Studies employing this strategy with enzymes superoxide dismutase (SOD) and glutathione peroxidase (GPX) have provided strong support for a relationship between antioxidant status and susceptibility to tissue injury (Reaume et al. 1996; Kondo et al. 1997; Yoshida et al. 1997; Schwartz et al. 1998; Spector et al. 1998; Fu et al. 1999; Jaeschke et al. 1999; Klivenyi et al. 2000). Although most of the studies performed to date do not explicitly address cumulative injury during aging, they implicitly address the genetic principles underlying why some individuals show more severe effects of aging and why some are more prone to neurodegenerative disease ( $\mathrm{H}$ alliwell 1992; Gotz et al. 1994) . Antioxidant knockout models, therefore, are useful for testing contributing factors to $A R H L$, especially given that a probably substantial proportion of ARH L is genetically related (Willott 1991; Schuknecht 1993; Gates et al. 1999).

There exists an attractive fit between one predicted property of at least some genetically related $A R H L$ and genetic impairment of ROS protections: Both predict a general state of vulnerability to insults. In keeping with this prediction, experiments in mice link both ARH L-related mutations and genetic impairment of ROS defenses to increased cochlear vulnerability. The murine Ahl gene (Li 1992a; Erway et al. 1996; Erway and Willott 1996; Johnson et al. 1997) and probably others ( Henry 1982; O hlemiller et al. 2000b) render the cochlea especially susceptible to noise. Knockout mice for Sod1, the gene coding for Cu/ Zn-SOD, show increased vulnerability to noise relative to wild types (O hlemiller et al. 1999a; McFadden et al. 2000) and increased cochlear degeneration with age (McFadden et al. 1999a; McFadden et al. 1999b; M cFadden et al. 2000). The impact of SOD deficiency in young adult mice (1-3 months old) was modest, yet an early and profound effect of such a mutation on hearing or cochlear vulnerability would not model the characteristics of ARHL very well.

The present study addresses the generality of the prediction that genetic impairment of ROS protections will lead to vulnerability of the cochlea, increased cumulative cochlear injury, and ARHL. Not all genetically based ARHL is likely to act through a "vulnerability" mechanism, and counterexamples already have been reported (Yoshida et al. 2000). This study examines the effect of inactivating the gene coding for celluIar GPx, which is the predominant form of glutathione peroxidase and the isoform believed to participate most widely in protecting cells from oxidative stress ( $\mathrm{Ho}$ et al. 1997; Brigelius-Flohe 1999). GPx utilizes glutathione (GSH) to reduce reactive peroxides and thus limit lipid peroxidation and minimize the production of highly toxic hydroxyl radical via Fenton and Haber-Weiss mechanisms (H alliwell 1992; Gotz et al. 1994; Evans and Halliwell 1999). A brief account of this work has appeared previously (Ohlemiller et al. 2000a).

\section{MATERIALS AND METHODS}

\section{Animals}

All procedures were approved by the CID Animal Care and U se Committee. The study included 33 mice of both sexes, eight weeks of age $( \pm 4 \mathrm{~d})$ at the time of noise exposure. Knockout (KO, $n=19$ ) and wild type mice ( $W T, n=15$ ) for the normal Gpxl gene were obtained directly from Dr. Ye-Shih H o. Gpxl knockout mice are physically indistinguishable from wild types and have the same life expectancy. They exhibit no neurological, musculoskeletal, or reproductive anomalies. Young adult CBA/CaJ mice (1-2 mo, $n=43$ ) were used for comparison of pre-exposure initial ABR thresholds.

To establish the Gpx1 knockout line, 129/ SVJderived embryonic stem cells containing a targeted mutation of Gpx1 were transplanted to C57BL/ 6 donor embryos. Germline positive chimeric males were bred to C57BL/ 6 females, and their heterozygous offspring were crossed. Mice used in the present study were the product of homozygous matings, hence no heterozygotes or littermates of differing genotype were tested. However, the mice were offspring of four KO and two WT mating pairs formed from progeny of a single heterozygous mating pair, so that the contributions of genetic modifiers were randomized. Additional details and procedures for genotyping of parentals are given elsewhere ( $\mathrm{Ho}$ et al. 1997).

\section{GPx tissue typing}

Livers (approximately $500 \mathrm{mg}$ ) were frozen in liquid nitrogen and kept at $-80^{\circ} \mathrm{C}$ for enzyme analysis and protein concentration. They were then homogenized in $50 \mathrm{mM}$ phosphate buffer ( $\mathrm{pH} 7.0$ ). GPx activity was quantified by monitoring the loss of NADPH at 340 
$\mathrm{nm}$ in a coupled-enzyme procedure at $37^{\circ} \mathrm{C}$ ( Prohaska 1991). Because tert-butyl hydroperoxide was used as the substrate, specificity of the assay for cellular GPx was not possible. H owever, cellular GPx is the predominant glutathione peroxidase in most tissues ( $\mathrm{H}$ o et al. 1997; Brigelius-Flohe 1999). O ne unit of GPx activity was defined as the amount of enzyme catalyzing the oxidation of $1 \mathrm{nmol}$ of NADPH per minute. Specific activity for GPx is reported as units/ mg protein. Protein content was determined by a modified Lowry protein assay using bovine albumin for reference (Markwell et al. 1978). Statistical tests on GPx activity were performed with SIGMASTAT (Jandel, San Rafael, CA).

\section{Noise exposure}

Noise exposures and auditory brainstem response recordings ( $A B R s)$ were performed in a foam-lined, double-walled sound proof room (Industrial Acoustics, Bronx, NY). The noise exposure apparatus consisted of a $21 \times 21 \times 11-\mathrm{cm}$ wire cage mounted on a pedestal inserted into a B\&K 3921 turntable. To ensure a uniform sound field, the cage was rotated at 1 revolution/ $80 \mathrm{~s}$ within a $42 \times 42-\mathrm{cm}$ metal bar frame. Motorola KSN 1020A piezo ceramic speakers (four total) were attached to each side of the frame. O pposing speakers were oriented nonconcentrically, parallel to the cage, and driven by separate channels of a Crown D150A power amplifier. Noise was generated by General Radio 1310 generators and bandpassed at 4.0-45.0 $\mathrm{kHz}$ by Krohn-H ite 3550 filters. The overall noise level was measured at the center of the cage using a $B \& K$ 4135 0.25-in. microphone in combination with a $B \&$ K 2231 sound level meter. Noise spectrum level was determined using a H ewlett Packard 3581A wave analyzer set at $300 \mathrm{~Hz}$ bandwidth and is shown elsewhere (Ohlemiller et al. 1999a). Animals were exposed in pairs for $1 \mathrm{~h}$ at $110 \mathrm{~dB}$ SPL. Spot measurements indicated that levels within the cage ranged from 110 to $113 \mathrm{~dB}$ SPL.

\section{ABR recordings}

Auditorybrainstem recordings were performed before noise exposure and 14 and 28 days after exposure. Animals were anesthetized ( $80 \mathrm{mg} / \mathrm{kg}$ ketamine, 15 $\mathrm{mg} / \mathrm{kg}$ xylazine, IP) and positioned dorsally in a custom headholder. Core temperature was maintained at $37.5 \pm 1.0^{\circ} \mathrm{C}$ using a thermostatically controlled heating pad in conjunction with a rectal probe (Yellow Springs Instruments Model 73A). Platinum needle electrodes (Grass, West War wick, RI) were inserted subcutaneously just behind the right ear (active), at the vertex (reference), and in the back (ground). Electrodes were led to a Grass P15 differential amplifier
(100-10,000 Hz, X 100), then to a custom amplifier providing another $X 1000$ gain, then digitized at 30 $\mathrm{kHz}$ using a Cambridge Electronic Design Microl401 in conjunction with SIGNAL TM (Cambridge Electronics, Canbridge, UK) and custom signal averaging software operating on a 120-M Hz Pentium PC. Sine wave stimuli generated by a Wavetek Model 148 oscillator were shaped by a custom electronic switch to 5-ms total duration, including $1 \mathrm{~ms}$ rise/ fall times. The stimulus was amplified by a Crown D150A power amplifier and output to a KSN 1020A piezo ceramic speaker located $7 \mathrm{~cm}$ directly lateral to the right ear, concentric with the external auditory meatus. Stimuli were presented freefield and calibrated using a B\&K 4135 0.25-in. microphone placed where the external auditory meatus would normally be. Toneburst stimuli at each frequency and level were presented 1000 times at $20 / \mathrm{s}$. The minimum sound pressure level required for visual detection of a response (short-latency negative wave) was determined at $5,10,20,28.3$, and $40 \mathrm{kHz}$ using a 5-dB minimum step size. The recording noise floor was typically about $0.2 \mu \mathrm{V}$. Statistical tests on ABR threshold data were performed with SIGMASTAT.

\section{Histology}

Cochleas were taken for histological evaluation within one week after final ABR testing. Animals were injected with sodium pentobarbital $(60 \mathrm{mg} / \mathrm{kg} \mathrm{IP})$ and perfused transcardially with cold $2.0 \%$ paraformaldehyde/ $2.0 \%$ glutaraldehyde in $0.1 \mathrm{M}$ phosphate buffer. Each cochlea was rapidly isolated and immersed in the same fixative, and the stapeswasimmediately removed. Complete infiltration of the cochlea by fixative was ensured by making a small hole at the apex of the cochlear capsule and gently circulating the fixative over the cochlea using a transfer pipette.

O ne cochlea from each animal was used for hair cell counts; the other was used to assess nerve fiber loss. For hair cell counts, cochleas were transferred to phosphate-buffered saline ( $\mathrm{pH}$ 7.4), dissected into half-turn segments, and stained in $\mathrm{H}$ arris' hematoxylin solution (McFadden et al. 1999b). Stained segments were whole-mounted in glycerin on glass slides. Surface preparations were examined using light microscopy at 400X magnification. The numbers of inner (IHC) and outer hair cells $(\mathrm{OHC})$ were counted in successive segments ( $0.24 \mathrm{~mm}$ average length) along the organ of Corti, beginning at the apex. The percent of hair cells missing was determined by comparing hair cell counts of individual mice to lab standards for normal CBA mice. For nerve fiber counts, fixed cochleas were decalcified (Decal, Baxter Scientific Products, Deerfield, IL) and embedded in Epon 812 resin. Serial sections ( $3 \mu \mathrm{m}$ thick) were made parallel 


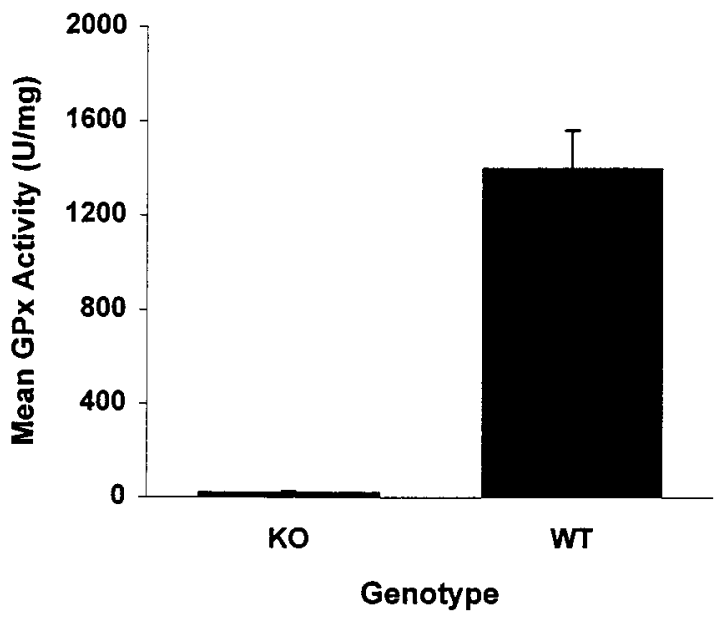

FIG. 1. Mean (+SD) GPx activity in liver of Gpx1 wild type (WT) and knockout $(\mathrm{KO})$ mice. One unit of activity corresponds to the reduction of $1 \mathrm{nmol} \mathrm{NADPH} / \mathrm{mg}$ protein/min. Differences by genotype are significant ( $t$ test, $p<<0.001$ ).

to the modiolar axis. Sections were stained with toluidine blue and examined under the light microscope. All nerve fibersin three apical and three basal habenulae were counted and averaged for each animal. No attempt was made to distinguish among type I and type II afferent or efferent fibers. Statistical tests on hair cell and nerve fiber data were performed with SPSS.

\section{RESULTS}

Tissue typing for GPx activity

Figure 1 compares mean GPx activity in whole liver of knockout and wild type mice. Specific activity is expressed in nanomoles of NADPH reduced per minute per milligram of protein in each sample. Enzyme activity showed perfect correspondence with genotype with no overlap, and the difference in activity by genotype was highly significant ( $t$ test, $p<<0.001$ ).

Pre- and postexposure thresholds

Figure 2 shows $A B R$ thresholds by genotype prior to noise exposure. Thresholds from similar-aged normal CBA mice have been included for comparison. Even before noise exposure, and despite the fact that the animals were only two months old, both WT and KO mice exhibited high-frequency hearing loss compared with CBAs. Thresholds in both genotypes averaged above $80 \mathrm{~dB}$ SPL at $40 \mathrm{kHz}$ and above $55 \mathrm{~dB}$ SPL at $28.3 \mathrm{kHz}$, while typical thresholds in normal CBA mice at these frequencies are below $40 \mathrm{~dB}$ SPL. Some degree of initial hearing loss was evident at frequencies as low

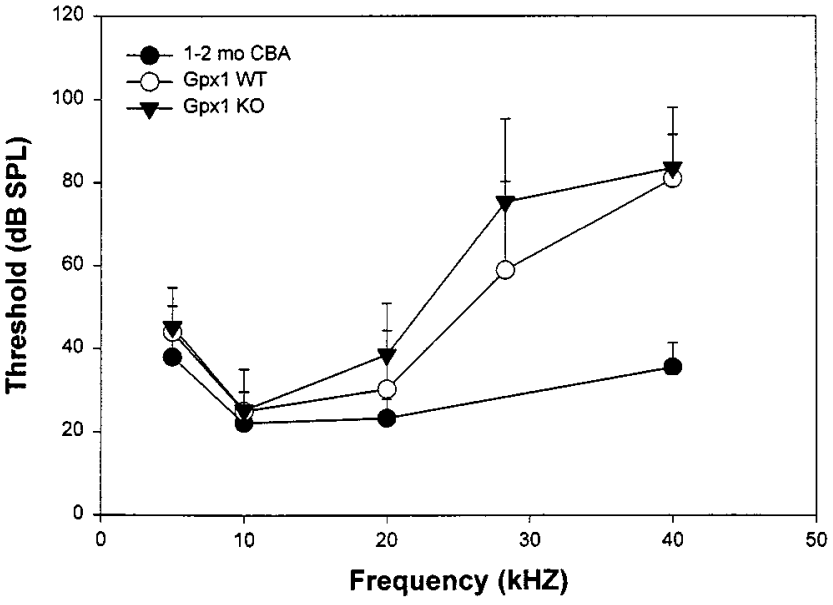

FIG. 2. Mean (+SD) hearing sensitivity in WT and KO mice determined by ABR thresholds prior to noise exposure. There are significant differences by genotype (two-way ANOVA, $p=0.006$ ). Similar-aged CBAs are shown for comparison. CBAs are from another study (Ohlemiller et al. 2000b) and were not tested at $28.3 \mathrm{kHz}$.

as $20 \mathrm{kHz}$, although it appeared less than $10 \mathrm{~dB}$ in WTs. For both genotypes, thresholds at $40 \mathrm{kHz}$ were considered too elevated to be informative so that statistical tests were applied only to results obtained at 5$28.3 \mathrm{kHz}$.

GPx deficiency led to significant elevation of $A B R$ thresholds prior to noise exposure ( two-way ANOVA, $p=0.006)$, with interactions between genotype and test frequency. Post hoc testing (Student-NewmanKeuls (SNK), $p<0.05$ ) detected a significant difference only at $28.3 \mathrm{kHz}$, where the magnitude of the effect was about $16 \mathrm{~dB}$ (Table 1).

Size of effect of Gpx1 knockout Figure 3 compares ABR thresholds by genotype two and four weeks after noise exposure. Permanent noise-induced threshold shifts were stable by two weeks. Because statistical analyses gave similar results at both time points, only fourweek results are described. G pxI KO mice showed significantly greater threshold elevation after exposure than WTs ( two-way ANOVA, $p<0.001$ ). Post hoc tests (SNK, $p<0.05)$ revealed significant differences at 20 and $28.3 \mathrm{kHz}$, where differences by genotype ranged from 15 to $23 \mathrm{~dB}$. Allowing for initial threshold differences, the contribution of GPx deficiency to noiseinduced hearing loss ( $\mathrm{NIHL}$ ) ranged from $\sim 0$ to 15 $\mathrm{dB}$ across all test frequencies (Table 1 ).

Although a significant main effect of genotype was detected, examination of the distribution of $A B R$ thresholds by test frequency (Fig. 4) suggests that analysis by Gpxl genotype alone may have underestimated the impact of GPx deficiency. Particularly after exposure, threshold distributions at 10,20 , and $28.3 \mathrm{kHz}$ were marked by high interanimal variance and the suggestion of multiple modes, although these were not sufficiently distinct to permit further analysis. O ne 


\begin{tabular}{|c|c|c|c|c|c|c|c|}
\hline \multicolumn{8}{|c|}{ TABLE 1} \\
\hline \multicolumn{8}{|c|}{ Size of effect Gpx1 knockout } \\
\hline \multirow[b]{2}{*}{$\begin{array}{l}\text { Mean threshold } \\
\quad(d B S P L) \text { at }\end{array}$} & \multicolumn{3}{|c|}{ Pre-exposure $^{a}$} & \multicolumn{3}{|c|}{4 weeks post $t^{a}$} & \multirow[b]{2}{*}{$\begin{array}{c}\text { Estimated contribution } \\
\text { of } K O \text { to } N I H L(d B)\end{array}$} \\
\hline & $W T$ & $K O$ & $\begin{array}{c}\text { Difference } \\
(d B)\end{array}$ & $W T$ & $K O$ & $\begin{array}{c}\text { Difference } \\
(d B)\end{array}$ & \\
\hline $5 \mathrm{kHz}$ & 44.0 & 45.3 & 1.3 & 51.7 & 51.8 & 0.1 & -1.2 \\
\hline $10 \mathrm{kHz}$ & 25.0 & 25.3 & 0.3 & 40.7 & 53.0 & 12.3 & 12.0 \\
\hline $20 \mathrm{kHz}$ & 30.3 & 38.6 & 8.3 & 51.9 & 74.8 & 22.9 & 14.6 \\
\hline $28.3 \mathrm{kHz}$ & 59.0 & 75.4 & 16.4 & 75.1 & 90.0 & 14.9 & -1.5 \\
\hline
\end{tabular}

${ }^{\mathrm{a}} \mathrm{KO}=$ knockout, $\mathrm{WT}=$ wild type for Gpx1.

${ }^{b}$ Significant by post hoc comparisons.

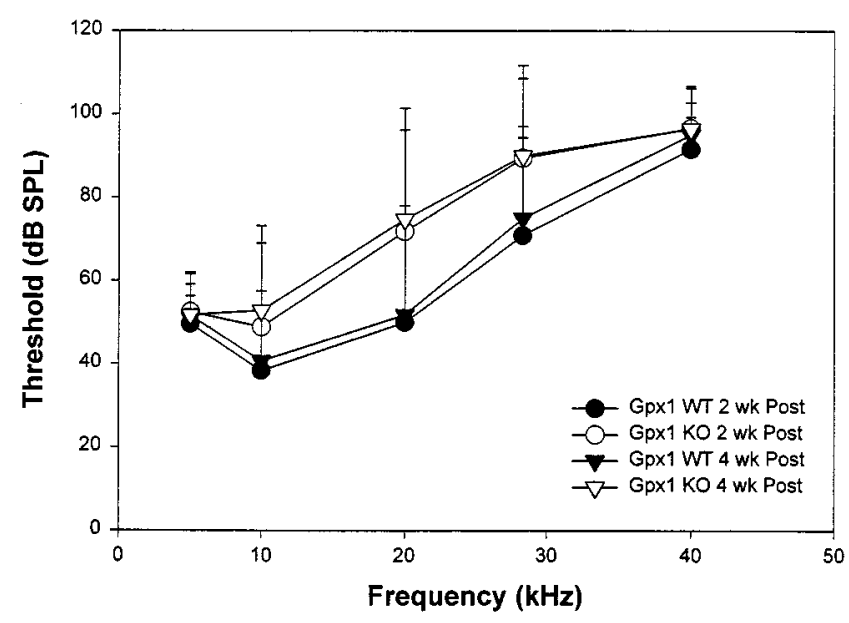

FIG. 3. Mean (+SD) hearing sensitivity in WT and KO mice compared two and four weeks post exposure. Noise-induced threshold shifts were stable. There are significant differences by genotype (twoway ANOVA, $p<0.001$ ).

interpretation of this distribution is the presence of additional unlinked genes that independently modulate noise vulnerability. Alleles of these genes would vary within Gpxl genotype since the mice were not inbred. H owever, increased variance in noise-induced threshold shifts relative to pre-exposure thresholdscan be observed even in inbred and F1 hybrid mice (O hlemiller et al. 2000b; O u et al. 2000a) and may be a result of environmental factors.

\section{Hair cell loss}

Noise-exposed Gpx1 knockouts showed greater hair cell loss than wild type controls. A significant main effect of genotype was found for both IH Cs (two-way ANOVA, $p=0.016)$ and OHCs $(p=0.035)$, with interactions between genotype and cochlear region. Both KO and WT mice had hair cell loss, essentially all of which was confined to the most basal $40 \%$ of the cochlea (Fig. 5.). This basal loss was more pronounced in GPx-deficient mice, however, for IHCS
( post hoc one-way ANOVA, $p=0.013$ ) and OHCs $(p=0.021)$. According to a recent frequency-place map for the mouse ( $\mathrm{Ou}$ et al. 2000b), the basal $40 \%$ of the cochlea should correspond to our three highest test frequencies ( $20-40 \mathrm{kHz}$ ), with $10 \mathrm{kHz}$ represented about $47 \%$ of the distance from the apex. Figure 6 presents an example of the use of hematoxylin staining to enhance recognition of hair cells and facilitate cell counts. Surface preparations taken from the lower cochlear base of an unexposed normal mouse (Fig. $6 \mathrm{~A})$ are compared with that taken from a noiseexposed Gpxl knockout mouse (Fig. 6B). Severe hair cell loss was sometimes associated with loss of the organ of Corti in restricted regions, but this was observed in both WTs and KOs. Thus, hair cell loss, and not the extent of degeneration, was the primary distinguishing feature between the KO and WT organ of Corti.

Nerve fiber loss

GPx deficiency also led to increased loss of cochlear nerve fibers in the exposed mice. A significant main effect of genotype was found (two-way ANOVA, $p=$ 0.002), with interactions between genotype and cochlear region. Both WTs and KOs showed significantly more nerve fibers per habenula in the apex than in the base (two-way ANOVA, $p<0.001$ ) (Fig. 7). Gpx1 KO mice showed nearly a $50 \%$ greater reduction in fibers/ habenula than WTs, however ( post hoc $t$ test, $p=0.002$ ). Figure 8 illustrates this difference in representative exposed WT and KO mice as it would appear for quantitation. Evacuated spaces within the bony channels suggest nerve fiber loss in both animals, but they are much more apparent in the knockout.

\section{DISCUSSION}

\section{Gpx1 knockout model}

Even prior to noise exposure, both Gpxl knockouts and wild types showed hearing loss at the highest test 

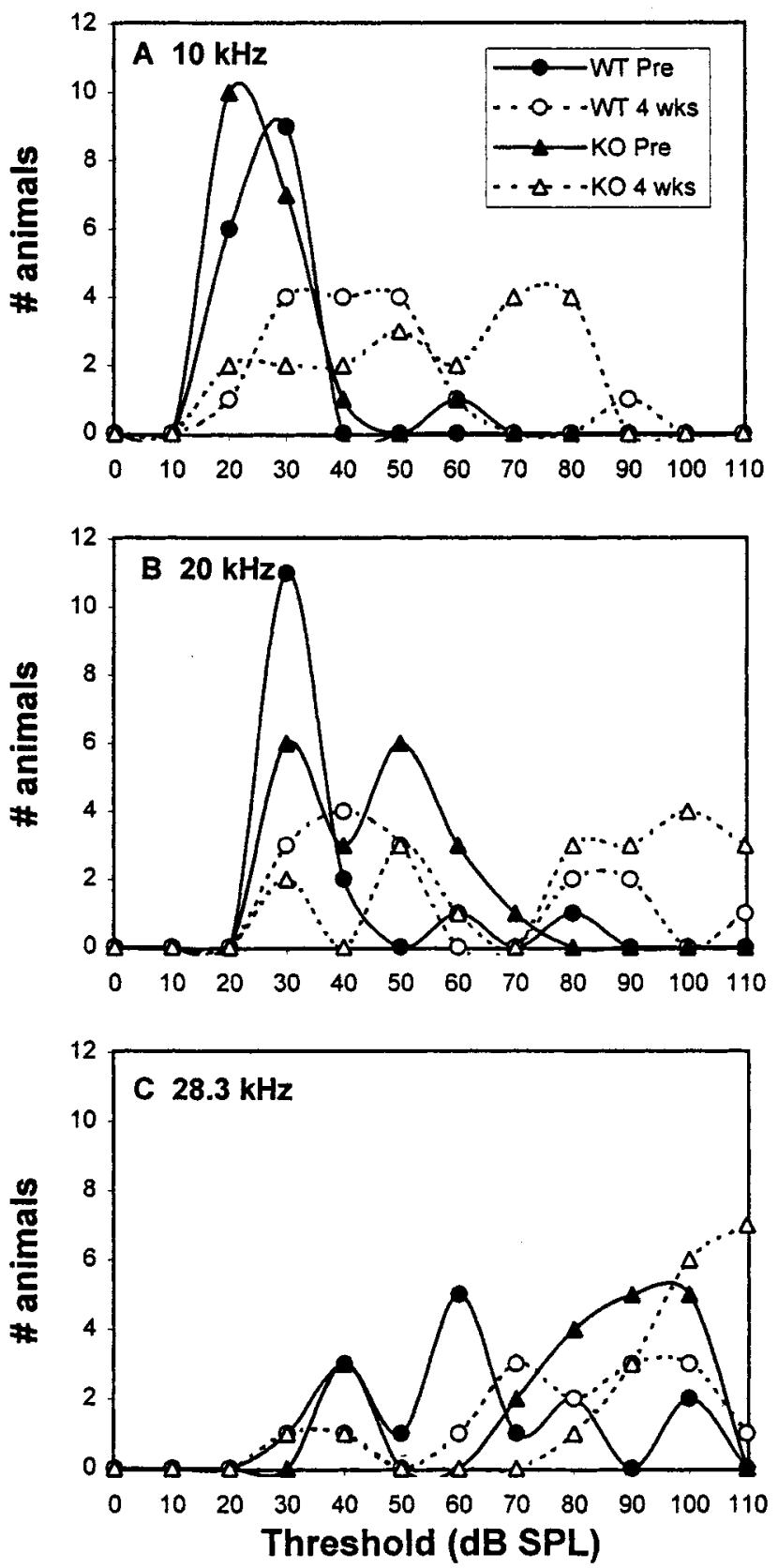

FIG. 4. Distribution of $A B R$ thresholds by genotype before noise exposure and four weeks later at 10, 20, and $28.3 \mathrm{kHz}$. Thresholds were assigned to $10-\mathrm{dB}$ bins. Lines are curvilinear fits.

frequencies. This hearing loss extended to lower frequencies in $\mathrm{KO}$, however, and was up to $16 \mathrm{~dB}$ greater in the $\mathrm{KO}$, depending on test frequency (Table 1 ). In neither KO nor WT mice was the initial hearing loss explicitly demonstrated to be age-related, yet this is a reasonable interpretation of this finding. The animals used in the study are a cross of C57 and 129 inbred strains, both of which show early and progressive cochlear degeneration that includes hair cell loss (Henry 1983; Li 1992b; Zheng et al. 1999). The absence of genetic complementation in our hybrids

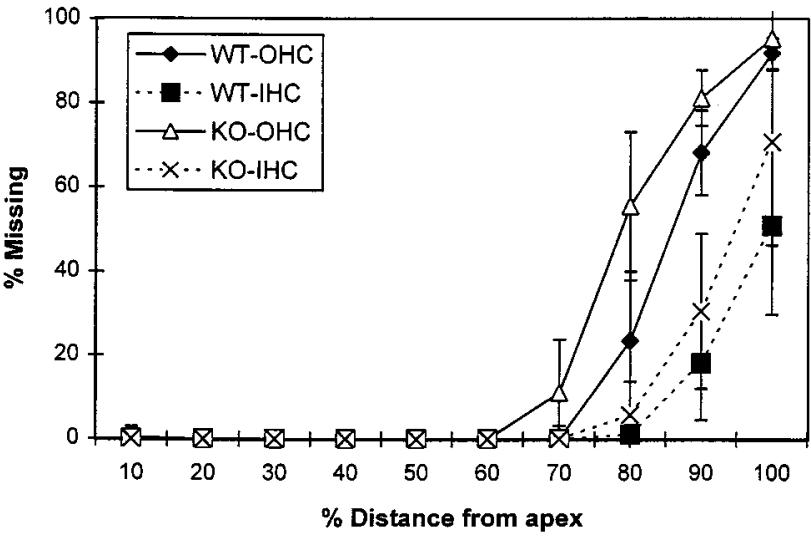

FIG. 5. Hair cell loss by genotype determined 4-5 weeks postexposure in hematoxylin-stained surface preparations. There were significant differences by genotype for both inner (two-way ANOVA, $p=0.016)$ and outer hair cells $(p=0.035) . \mathrm{IHC}=$ inner hair cell, $\mathrm{OHC}=$ outer hair cell.

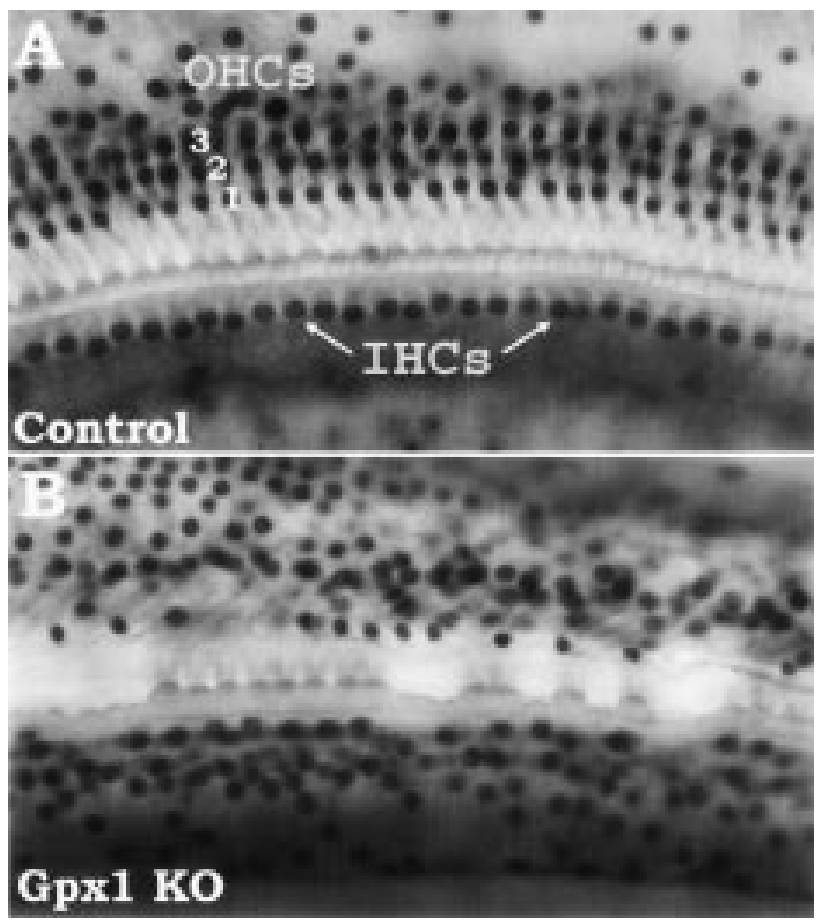

FIG. 6. Representative surface preparations from (A) a normal control mouse and (B) noise-exposed Gpx1 KO as they are viewed for hair cell counts. $\mathrm{IHC}=$ inner hair cell, $\mathrm{OHC}=$ outer hair cell.

suggests that both may carry the Ahl mutation, known to be carried by C57BL/ 6 mice (Johnson et al. 1997). The fact that KO s and WTs exhibited the largest initial threshold differences at the highest test frequencies suggests that GPx deficiency may magnify the influence of A hl (or another similar-acting gene). Any hearing loss based on such interactions is very likely to be progressive and, thus, age-related.

GPx-deficient mice also showed increased susceptibility to NIHL. Although this effect was clear, it was 


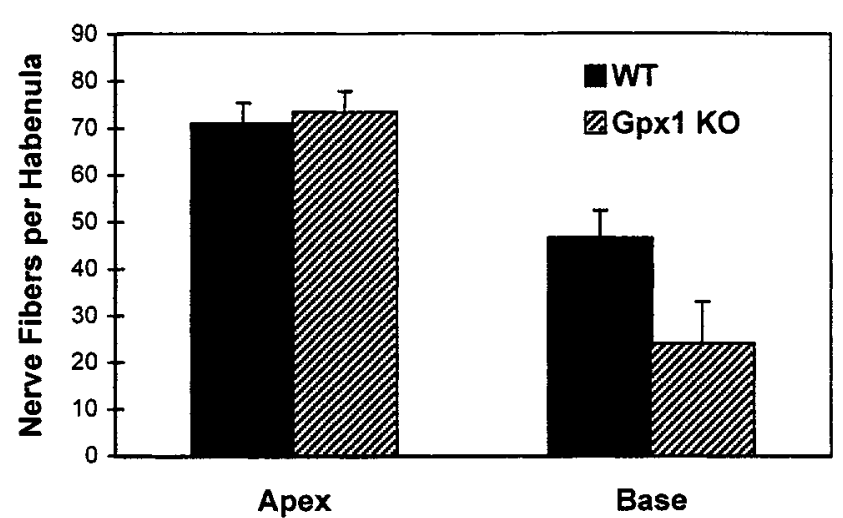

FIG. 7. Comparison of nerve fiber density in the cochlear apex and base of WTs and KOs. Density of fibers in the apex and base differed significantly (two-way ANOVA, $p<0.001$ ) for both genotype. Knockout mice showed significantly fewer fibers within the base ( $t$ test, $p=0.002)$

modest and it varied with test frequency. The contribution of the knockout to hearing loss ranged from $\sim 0$ $\mathrm{dB}$ at $5 \mathrm{kHz}$ to an estimated $15 \mathrm{~dB}$ at $20 \mathrm{kHz}$ (Table 1). Apparent age-related hearing loss at $28.3 \mathrm{kHz}$, also attributable to GPx deficiency, probably reduced the noise-induced component of hearing loss at this frequency. Given the increasing impact of the $\mathrm{KO}$ with frequency (Table 1 ), an effect of the $\mathrm{KO}$ on NIHL would likely otherwise have been found at $28.3 \mathrm{kHz}$ also. Conclusions regarding the extreme cochlear base were hampered by a high-frequency hearing loss and cochlear degeneration common to both genotypes. If GPx deficiency promotes injury that may present as $A R H L$, then is is also true that no clear distinction between the influence of GPx deficiency on ARHL and NIHL can be assigned in our data. Initial highfrequency hearing losses could have been caused in part by inadvertent noise exposure ( e.g., animal facility noise, shipping) or other influences.

GPx deficiency was also associated with greater hair cell and nerve fiber loss, at least within the cochlear base. Because cell counts were not obtained from unexposed animals, this degeneration cannot be attributed with certainty to the effects of aging versus noise. Note, however, that the spatial patterns of hair cell losses observed in both KO and WT mice are more consistent with pre-exposure hearing thresholds than with postexposure thresholds. $\mathrm{OHC}$ losses in $\mathrm{KO}$ mice extended $40 \%$ of the distance from the base, consistent with initial hearing losses at $20 \mathrm{kHz}$ and above ( $\mathrm{Ou}$ et al. 2000b). Similarly, O H C losses in WT mice extended only about $30 \%$ of the distance from the base, in keeping with their near-normal thresholds at $20 \mathrm{kHz}$. By contrast, hair cell loss did not extend far enough apically to account well for the observed NIHL in either KO or WT mice. Therefore, it seems likely that it was the pre-existing "age-related" component of hair cell and nerve fiber loss that was increased by GPx deficiency, as reflected in our measurements. It is not surprising that hair cell loss did not correspond well with the frequency range of NIHL in our mice. Several reports have described the general inability of hair cell loss to "explain" NIHL in mice (Fowler et al. 1995; O hlemiller et al. 1999b; Yoshida et al. 1999; Ou et al. 2000a), although there may be a better correspondence in young adult mice (O hlemiller et al. 2000b). To account for NIHL, other nonlethal injuries to hair cells (e.g., Yoshida et al. 1999) must be invoked.

\section{Role of genetic background}

The impact of genetic background in this and similar studies merits discussion. First, it is important to distinguish between the two major types of influence that genetic background may have. Most knockout and transgenic mouse studies involve hybrid mice, reflecting the methodological convenience of inserting genes into certain strains that other wise may be disadvantageous by other criteria (Crusio 1996; Lathe 1996; Choi 1997). Repeated sibling crosses over 10-20 generations eventually yields the genetic standardization of a new mouse substrain or strain, while backcrossing to one of the parental strains more rapidly moves the transgene to a congenic background that asymptotically approaches that parental strain (Green 1975). It is in the transition that our animals-and those used in the vast majority of similar studies-are produced and evaluated. Such animals are neither completely hybrid nor inbred. Both hybrid and inbred models have their advantages and drawbacks. However, as we shall explain, most studies are subject to some limitations of both.

$\mathrm{H}$ ybrids are heterozygous at many loci, approximating the situation in humans, and provide a model in which an effect of the transgene or KO should be seen if the gene of interest is truly important. H ybrid models involving outbred strains, such as CD1, can be even more demonstrative in this regard. However, studies seeking to uncover subtle effects, such as the current study, are subject to increased variance in the data obtained. This variance is caused by genetic modifiers that vary from animal to animal, independent of the gene under study. In such cases, any effects of the transgene or KO maybe partiallyobscured and thereby underestimated. This limitation is unlikely to lead to inflated effects. H owever, negative results must be carefully interpreted. If fortune prevails, the distribution of the data may reveal an order, such as discernible peaks, allowing some sources of variance in the data to be factored out. In our previous study of Sod1 KO mice (O hlemiller et al. 1999a), this feature of the data made it possible to compare subsets of KO and WT mice so that a more accurate determination of the 


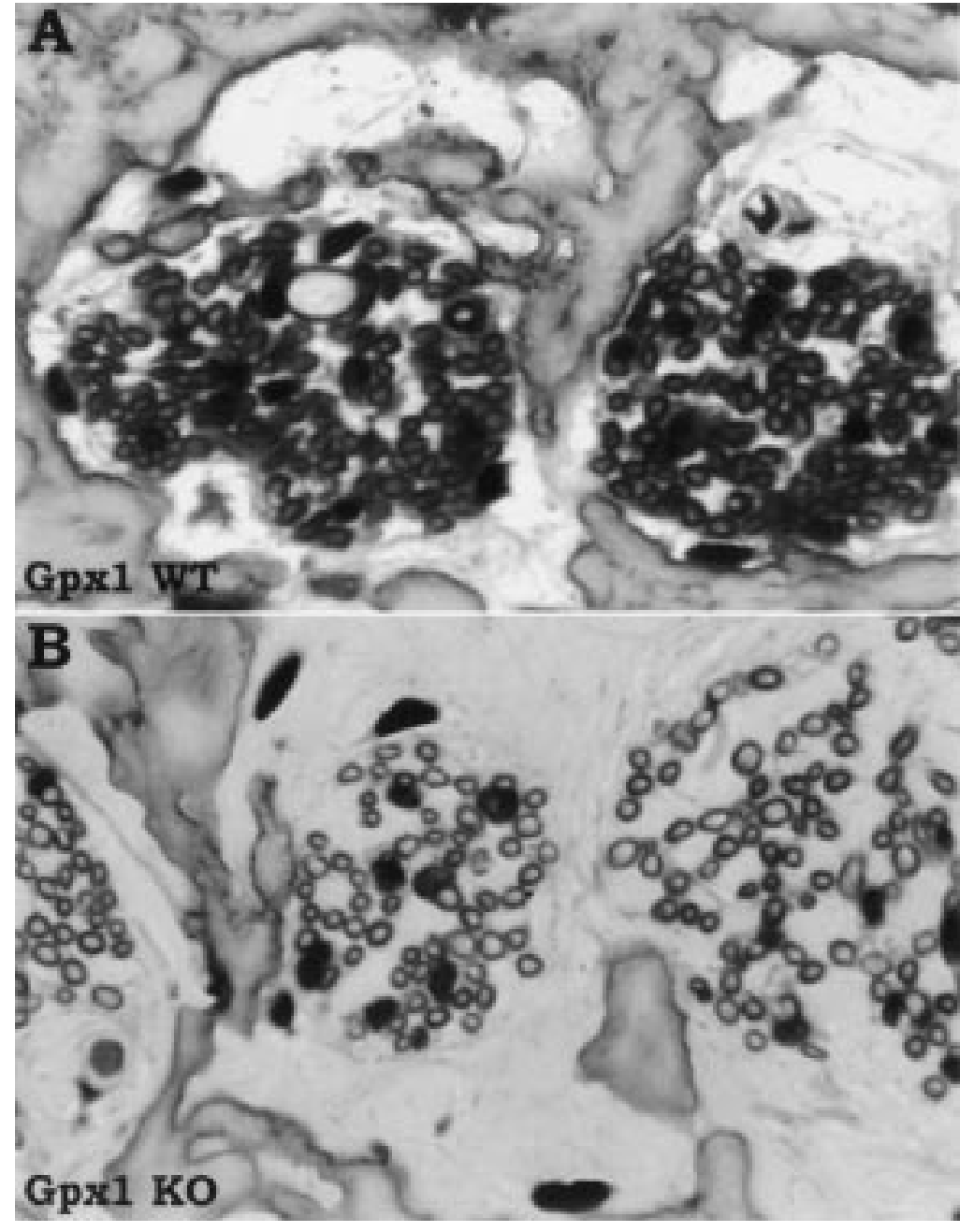

FIG. 8. Light photomicrographs of representative habenula perforata in the cochlear base of exposed (A) WT and (B) KO mice as they are viewed for nerve fiber counts. The plane of section is parallel to the modiolar axis. effects of SOD deficiency could be obtained. In the present study, the data were similarly marked by a high degree of variance within Gpxl genotype, and, again, the primary contributor was probably the influence of additional genes. However, there was no clear underlying order in the threshold distribution that might have permitted the separation of animals for comparison by subgroups. The likely result of analysis by $G p x 1$ genotype alone was an underestimate of the effects of the knockout. Another possible factor is the increase in variance of thresholds that is often observed following noise exposure, even in inbred and F1 hybrid mice (Ohlemiller et al. 2000b; Ou et al. 2000a). This may reflect differences in susceptibility resulting from unknown and unintended environmental conditioning or slight differences in the noise exposure itself.

Inbred models eliminate obscurating of results caused by genetic heterogeneity of the sample. However, few inbred strains will be found to be "neutral" in terms of their impact on the observed phenotype of a KO or transgenic model, and no strain can be assumed a priori to be superior for a given study (Crusio 1996; Lathe 1996; Choi 1997). Cases abound in the literature of murine mutations whose associated phenotype varies, depending on the strain. For example, the $\mathrm{rd} 3$ retinal degeneration mutation gives rise to widely varying phenotypes on different strains ( $\mathrm{H}$ eckenlively et al. 1993). The tub mutation, which arose in C57BL / 6, has generated much interest for its pleiotropic effects on hearing, vision, and body weight (Ohlemiller et al. 1997). Yet, its presence might go undetected on a different inbred strain (I keda et al. 1999). U sually, the genetic modifiers that underlie such strain dependence are unknown. Even if genes known to be present are potential modifiers (by virtue of a known impact on the trait that is being measured), the nature of their interaction with the $\mathrm{KO}$ or transgene cannot be predicted. The implication of these observations is that no one model should be assumed to provide a definitive answer regarding the effect of any KO or transgene. Instead, any one model indicates one possible outcome. Within this framework, our present and previous results in Gpxl and Sod 1 KO s support a principle whereby genetic impairment of antioxidant defenses appears capable of promoting cochlear injury and ARHL. 
$\mathrm{H}$ ybrid backgrounds are not immune to issues of strain dependence. Crossing inbred stains leads to somewhat limited genetic variability since the parent strains are homozygous at essentially all loci. Because of this, some or all animals in the sample may be homozygous for mutations that could influence results. In the present study, as well as our study of Sod1 knockout mice (Ohlemiller et al. 1999a), the combination of two strains used in generating the animals led to an initial high-frequency hearing loss. O ur analysis of Sod1 KO sindicated that mutation(s) responsible for this hearing loss acted independently of the effects of SOD deficiency. By contrast, in Gpx1 KOs the effect of the knockout may be to amplify the effect of $\mathrm{Ahl}$ or another mutation, based on the observed spatial pattern of hearing and cell loss. Like most other investigators, we did not have the luxury of picking from many KO models but used the models that were available. These models were developed on backgrounds chosen not for their hearing ability but for their advantages in gene manipulation, as was stated. Nearly every knockout model for which basic auditory sensitivity has been adequately described involves the inbred C57 and 129 strains and the outbred CD1 strains and features age-related hearing loss (Shone et al. 1991; Zheng et al. 1999). Given a choice, we would not have picked such models for our initial studies. However, from the foregoing, we would strongly argue that these models are not inherently any less suitable than other models. Indeed, it would be desirable to examine the effect of genetic impairment of antioxidant enzymes explicitly on one or more backgrounds that include deafness genes. As it happens, that is where we began.

\section{GPx, glutathione, and oxidative cochlear injury}

$\mathrm{H}$ ydrogen peroxide, the primary substrate of cellular GPx, participates in both Fenton and Haber Weiss reactions, the two key reactions that lead to the formation of the highly toxic hydroxyl radical ( $\mathrm{H}$ alliwell 1992; Gotz et al. 1994; Evans and Halliwell 1999). By its action in regulating cellular levels of peroxide, GPx plays a critical role in minimizing the production of hydroxyl radical. Although there may be species differences (Lautermann et al. 1997), GPx appears present at comparatively high levels in the cochlea (Pierson and Gray 1982). To sustain its activity, cellular GPx requires selenium and glutathione, so that deficiencies in these as well as in GPx itself might produce similar effects. One recent study involving GSH depletion prior to noise exposure, combined with the present results, permits comparison of the effects of chronic and acute impairment of GSH -dependent antioxidant defenses. That study (Yamasoba et al. 1998) involved a different noise-exposure paradigm and a different animal model (guinea pig), yet it produced results strikingly similar to those of the present work. Among the features reproduced were the approximate magnitude of the effect in $\mathrm{dB}$, an increased effect at higher frequencies, and hair cell loss. This is particularly surprising, since depletion of GSH should cripple not only GPx but also GSH transferases, which have some overlapping actions with GPx (Ketterer 1998), as well as nonenzymatic antioxidant functions of GSH itself. Other studies have also shown that GSH depletion enhances ototoxic injury, which probably also reflects impairment of each of these functions ( $\mathrm{H}$ offman et al. 1988; Hu et al. 1999).

Significance of GPx versus other antioxidant enzymes

Based on models examined so far, the impact of SOD deficiency appears generally comparable to that of GPx deficiency. Both contribute modestly to cochlear susceptibility and apparent ARHL without lethality, CNS pathology, or dramatic hearing loss. It is not clear why the impact of SOD deficiency should be similar to that of GPx deficiency with respect to the magnitude of their effects on NIHL. SOD and GPx perform different functions. SO D deficiency may yield modest results because SO D removes a toxic radical (superoxide) yet produces another reactive intermediate (peroxide). Both substrate and product take part in the production of hydroxyl radical. Superoxide al so contributes to the production of peroxynitrite (Halliwell 1992; Gotz et al. 1994; Evans and $\mathrm{H}$ alliwell 1999), whose role in noise injury is not well understood. In sum, both decreases and increases in SOD activity may be offset. The primary action of GPx - removing a toxic intermediatewould be expected to be more straightforward. In addition, GPx may remove peroxynitrite (Sies et al. 1997), potentially compounding its beneficial actions. Experiments with transgenic overexpressors of SOD and GPx, or acute addition of these enzymes, have shown a greater effect of GPx than either SOD or catal ase (Weisbrot-Lefkowitz et al. 1998). N evertheless, there may exist sufficient redundancies in antioxidant protections so that the effect of removing any one component is partly mitigated. There are multiple isoforms of both of these enzymes, although these isoforms are present in much smaller amounts and located in different compartments (Carrlson et al. 1995; Li et al. 1995; Brigelius-Flohe 1999). There is also some duplication of function by other enzymes such as GSH transferases (which detoxify some types of hydroperoxides) (Ketterer 1998) and catalase. Any compensation by other enzymes apparently does not, however, involve up-regulation of these in the absence of cellular GPx (Cheng et al. 1997; Ho et al. 1997). Finally, GSH does not require the presence of GPx to 
perform a significant antioxidant role. The fact that the current GPx results are similar to those obtained in acute experiments involving impairment of GSH dependent antioxidant systems (Yamasoba et al. 1998) raises the possibility of an upper limit to the effect of crippling any subset of antioxidant protections.

\section{Relevance to age-related hearing loss}

Genetic impairment of antioxidant protections can lead to both age-related and noise-induced hearing loss, apparently by conferring a state of vulnerability on the cochlea (McFadden et al. 1999a; O hlemiller et al. 1999a; McFadden et al. 2000). Knockout models of this type resemble the expected interplay of genes and some human acquired hearing loss, whereby genetically susceptible individuals sustain cumulative cochlear damage that presents as ARHL. That ARHLrelated genes exist, and that some of these may work in this manner, has been speculated ( H enry 1982; Willott 1991; Schuknecht 1993). The murine Ahl mutation provides a specific example ( Li 1992a; Erway et al. 1996; Erway and Willott 1996; Johnson et al. 1997), although there is no evidence that it directly affects antioxidant defenses. Thus, it is possible that genetic impairment of antioxidant defenses underlies some ARHL in humans. Most of the studies dealing with oxidative injury to the cochlea have focused on a handful of enzymes, such as GPx, SOD, and GSH transferases. Certainly, mutations that impair specific isoforms of these may be involved. Just as likely, however, are mutations of an unknown number of genes that impact cellular redox status or coordinately regulate antioxidant defenses.

\section{ACKNOWLEDGMENTS}

We thank Jaci Lett for assistance with figure preparation and Dr. Barbara Bohne for comments on the manuscript. Supported by the Edward Mallinckrodt, Jr. Foundation (KKO), NIH R01 DC03454 (KKO), and NIH R01 HL56421 (YSH).

\section{REFERENCES}

BRIGELIUS-FLohe R. Tissue-specific functions of specific glutathione peroxidases. Free Rad. Biol. Med. 27:951-965, 1999, DOI: 10.1016/ S0891-5849, (99), 00173-2.

CARRLSOn LM, JonsSON J, EdLUnd T, MarkLund SL. Mice lacking extracellular superoxide dismutase are more sensitive to hyperoxia. Proc. Nat. Acad. Sci. 92:6264-6268, 1995.

Cheng W-S, Ho Y-S, Ross DA, Valentine BA, Combs GF, Lei XG. Cellular glutathione peroxidase knockout mice express normal levels of selenium-dependent plasma and phospholipid hydroperoxide glutathione peroxidases in various tissues. J. Nutrit. 127:1445-1450, 1997.
CHOI D. Background genes: O ut of sight, but not out of brain. TINS. 11:499-500, 1997.

Clerici WJ, Hensley K, Dimartino DL, Butterfield DA. Direct detection of ototoxicant-induced reactive oxygen species generation in cochlear explants. Hear. Res. 98:116-124, 1996, DOI: 10.1016/ 0378-5955, (96), 00075-5.

Crusio WE. Gene-targeting studies: New methods, old problems. TINS. 19:186-187, 1996

ERWAY LC, ShIAU Y-W, Davis RR, KReIG EF. Genetics of age-related hearing loss in mice. III. Susceptibility of inbred and F1 hybrid strains to noise-induced hearing loss. H ear. Res. 93:181-187, 1996, DOI:10.1016/ 0378-5955, (95), 00226-X.

ERWAY LC, WILLOTT JF. Genetic susceptibility to noise-induced hearing loss. AXELSSON A Scientific Basis of Noise-Induced Hearing Loss. Thieme New York 56-64, 1996.

EVANS P, HaLliWell B. Free radicals and hearing: Cause, consequence and criteria. Ann. NY Acad. Sci. 884:19-40, 1999.

Fowler T, CANLon B, Dolan D, Miller JM. The effect of noise trauma following training exposures in the mouse. Hear. Res. 88:1-13, 1995, DOI:10.1016/ 0378-5955, (95), 00062-9.

Fu Y, CHENG WH, PorRes JM, Ross DA, LEI XG. Knockout of cellular glutathione peroxidase renders mice susceptible to diquatinduced oxidative stress. Free Rad. Biol. Med. 27:605-611, 1999, DOI:10.1016/ S0891-5849, (99), 00104-5.

Garetz SL, Altschuler RA, Schach J J. Attenuation of gentamicin ototoxicity by glutathione in the guinea pig in vivo. Hear. Res. 77:81-87, 1994a.

GARETZ SL, RhEe DJ, SCHACHT J. Sulfhydryl compounds and antioxidants inhibit cytotoxicity to outer hair cells of a gentamicin metabolite in vitro. Hear. Res. 77:75-80, 1994b.

Gates GA, Couropmitree N N, Myers RH. Genetic associations in age-related hearing thresholds. Arch. Otolaryngol. Head Neck Surg. 125:654-659, 1999.

Gotz ME, Kunig G, Riederer P, Youdim MBH. Oxidative stress: free radicals production in neural degeneration. Pharmaceut. Ther. 63:37-122, 1994.

Green EL. Breeding systems. EL Green, Biology of the Laboratory Mouse (2nd revised ed.). Dover Publications, New York, 11-22, 1975.

H ALLIWELL B. Reactive oxygen species and the central nervous system. J. Neurochem. 59:1609-1623, 1992.

HaRman D, PietTe L. Free radical theory of aging: Free radical reactions in serum. J. Gerontol. 21:560-565, 1960.

Heckenlively JR, Chang B, Peng C, Hawes NL, Roderick TH. Variable expressivity of $\mathrm{rd}-3$ retinal degeneration dependent on background strain. In: JG Hollyfield (ed) Retinal degeneration. Plenum, New York, 273-281, 1993.

HENRY KR. Influence of genotype and age on noise-induced auditorylosses. Behav. Gen. 12:563-573, 1982.

HENRY KR. Ageing and audition. In: JF Willott (ed) The auditory psychobiology of the mouse. Charles C. Thomas, Springfield, IL 470-494, 1983.

HiROSE K, HOCKENBERY DM, RUbel EW. Reactive oxygen species in chick hair cells after gentamicin exposure in vitro. Hear. Res. 104:1-14, 1997, DOI:10.1016/ S0378-5955, (96), 00169-4.

Ho Y-S, Magnenat JL, Bronson RT, CaO J, Gargano M, Sugawara $M$, Funk CD. Mice deficient in cellular glutathione peroxidase develop normally and show no increased sensitivity to hyperoxia. J. Biol. Chem. 26:16644-16651, 1997.

Hoffman DW, Jones-King KL, Whitworth CA, Rybak LP. Potentiation of ototoxicity by glutathione depletion. Ann. Otol. Rhinol. Laryngol. 97:36-41, 1988.

Hu BH, McFadden SL, Salvi RJ, Henderson D. Intracochlear infusion of buthionine sulfoximine potentiates carboplatin ototoxicity in the chinchilla. Hear. Res. 128:125-134, 1999, DOI:10.1016/ S0378-5955, (98), 00210-X.

Hu BH, Zheng XY, McFadden S, Henderson D. The protective 
effects of R-PIA on noise-induced hearing loss. H ear. Res. 113:198206, 1997, DOI:10.1016/ S0378-5955, (97), 00143-3.

I Keda A, Zheng QY, Rosenstiel P, Maddatu T, Zuberi AR, RoopeNIAN DC, NORTh MA, NAggert JK, JOHNSON KR, Nishina PM. Evidence for modification of hearing in tubby mice: Evidence for the existence of a major gene (moth 1 ) which protects tubby mice from hearing loss. Human Mol. Genet. 8:1761-1767, 1999.

JaESCHKE H, HO Y-S, Fisher MA, LAWSEN JA, FARH oOd A. Glutathione peroxidase deficient mice are more susceptible to neutrophilmediated hepatic parenchymal cell injury during endotoxemia: Importance of an intracellular oxidant stress. Hepatology. 29:443450, 1999.

JohnSON KR, ERWAY LC, COOK SA, WILLOTT JF, ZhENG QY. A major gene affecting age-related hearing loss in C57BL/ 6J mice. H ear. Res. 114:83-92, 1997, DOI:10.1016/ S0378-5955, (97), 00155-X.

KeTtereR B. Glutathione S-transferases and prevention of cellular free radical damage. Free Rad. Res. 28:647-658, 1998.

Kliveny P, Andreassen OA, Ferrante RJ, Dedeoglu A, Mueller G, Lancelot E, Bogdanov M, Andersen JK, Jiang D, Beal MF. Mice deficient in cellular glutathione peroxidase show increased vulnerability to malonate, 3-nitroproprionic acid, and 1-methyl4-phenyl-1,2,5,6-tetrahydropyridine. J. Neurosci. 20:1-7, 2000.

Kondo T, Reaume AG, huang T-T, Carlson E, Murakami K, Chen SF, Hoffman EK, Scott RW, Epstein CJ, Chan PH. Reduction of CuZn-superoxide dismutase activity exacerbates neuronal cell injury and edema formation after transient focal cerebral ischemia. J. Neurosci. 17:4180-4189, 1997.

Kopke RD, Liu W, Gabaizedah R, Jacono a, Feghali J, Spray D, Garcia P, Steinman H, Malgrange B, Ruben RJ, Rybak L, Van DE WATER TR. Use of organotypic cultures of Corti's organ to study the protective effects of antioxidant molecules on cisplatininduced damage of auditory hair cells. Am. J. Otol. 18:559571, 1997.

LATHE R. Mice, gene targeting and behaviour: More than just genetic background. TINS. 19:183-186, 1996

Lautermann J, Crann Sa, McLauren J, Schacht J. Glutathionedependent antioxidant systems in the mammalian ear: effects of aging, ototoxic drugs and noise. Hear. Res. 114:75-82, 1997, DOI:10.1016/ S0378-5955, (97), 00154-8.

LI HS. Influence of genotype and age on acute acoustic trauma and recovery in $\mathrm{CBA} / \mathrm{Ca}$ and $\mathrm{C} 57 \mathrm{BL} / 6 \mathrm{~J}$ mice. Acta Otolaryngol. 112:956-967, 1992a.

LI H-S. Genetic influences on susceptibility of the auditory system to aging and environmental factors. Scand. Audiol. Suppl. 36: 1-39, 1992b.

li Y, Carlson Ej, Melov S, Ursell PC, Olson Jl, Noble LJ, Yoshimura MP, Berger C, Chan PH, Wallace DC, EpStein CJ. Dilated cardiomyopathy and neonatal lethality in mutant mice lacking manganese superoxide dismutase. Nat. Genet. 11:376-381, 1995.

MARKWELL MAK, H AAS SM, Bieber LL, Tolbert NE. A modification of the Lowery procedure to simplify protein determination in membrane and lipoprotein samples. Anal. Biochem. 87:206210, 1978.

McFadden SL, Ding D, Burkard RF, Jiang H, Reaume AG, Flood DG, SALVI RJ. Cu/ Zn SOD deficiency potentiates hearing loss and cochlear pathology in aged 129,CD-1 mice. J. Comp. Neurol. 413:101-112, 1999a, DOI:10.1002/ (SICI) 1096-9861, (19991011), 413:1<101::AID-CNE7 73.0.CO;2-L.

McFadden SL, Ding D, Reaume AG, Flood DG, Salvi RJ. Agerelated cochlear hair cell loss is enhanced in mice lacking copper/ zinc superoxide dismutase. Neurobiol. Aging. 20:1-8, 1999b, DOI:10.1016/ S0197-4580, (99), 00018-4.

McFadden SL, Ding D-L, OHLemiller KK, Salvi RJ. The role of superoxide dismutase in age-related and noise-induced hearing Ioss: Cluesfrom Sod1 knockout mice. In: Willott (ed) JF, H andbook of M ouse Auditory Research: From Behavior to Molecular Biology. CRC Press, New York 2000 in press.
OHLEMILLER KK, DUGAN LL. Elevation of reactive oxygen species following ischemia-reperfusion in mouse cochlea observed in vivo. Audiol. Neuro-O tol. 4:219-228, 1999.

OHLemiller KK, Hughes RM, Lett JM, Ogilvie JM, SPeCK JD, WRIGHT JS, FADDIS BT. Progression of cochlear and retinal degeneration in the tubby (rd5) mouse. Audiol. Neuro-Otol. 2:175185, 1997.

O HLEMILLER KK, LEAR PM, H o Y-S. Deficiency of cellular glutathione peroxidase increases noise-induced hearing loss in young adult mice. Abst. Assn. Res. Otolaryngol. 23:219, 2000a.

Ohlemiller KK, McFadden SL, Ding D-L, Reaume AG, Hoffman EK, Scott RW, Wright JS, Putcha GV, Salvi RJ. Targeted deletion of the cytosolic $\mathrm{Cu} / \mathrm{Zn}$-superoxide dismutase gene (SOD1) increases susceptibility to noise-induced hearing loss. Audiol. Neuro-O tol. 4:237-246, 1999a.

OHLEMILLER KK, WRIGHT JS, DUGAN LL. Early elevation of cochlear reactive oxygen species following noise exposure. Audiol. N euroOtol. 4:229-236, 1999b.

OHLEMILLER KK, Wright JS, HeIDbreder AF. 2000b Vulnerability to noise-induced hearing loss in "middle-aged" and young adult mice: Adose-response approach in CBA, C57BL, and BALB inbred strains. Hear. Res. (in press).

OU HC, Bohne BA, Harding GW. Noise damage in the C57BL/ CBA F1 mouse cochlea. Hear. Res. 145:111-122, 2000a.

OU HC, HARDING GW, BOHNE BA. An anatomically based frequencyplace map for the mouse. Hear. Res. (in press) 145:123-129, 2000b.

Pierson MG, Gray BH. Superoxide dismutase activity in the cochlea. Hear. Res. 6:141-151, 1982.

PROHASKA JR. Changes in Cu/ Zn-superoxide dismutase, cytochrome c oxidase, glutathione peroxidase and glutathione transferase activities in copper-deficient mice and rats. J. Nutrit. 121:355363, 1991.

Reaume AG, Elliott Jl, Hoffman KK, Kowall NW, Ferrante RJ, SiWEK DF, Wilcox HM, FLoOd DG, BeAL MF, BRoWn RHJ, SCOTT RW, SNIDER WD. Motor neurons in the $\mathrm{Cu} / \mathrm{Zn}$ superoxide dismutase-deficient mouse develop normally but exhibit enhanced cell death after axonal injury. Nat Genet. 13:43-47, 1996.

SCHUKNECHT HF 1993 Pathology of the Ear. Lea and Febiger, Philadelphia.

Schwartz PJ, Reaume A, Scott R, Coyle JT. Effect of over- and under-expression of $\mathrm{Cu} / \mathrm{Zn}$-superoxide dismutase on the toxicity of glutamate analogs in the transgenic mouse striatum. Brain Res. 789:32-39, 1998, DOI:10.1016/ S0006-8993, (97), 01469-8.

SEIDMAN MD, QUIRK WS. The protective effects of tirilated mesylate (U 74006F) on ischemic and reperfusion-induced cochlear damage. Otolaryngol. Head Neck Surg. 105:511-516, 1991.

Seidman MD, Quirk WS, Nuttall AL, Schweintzer VG. The protective effects of allopurinol and superoxide dismutase-polyethylene glycol on ischemic and reperfusion-induced cochlear damage. Otolaryngol. Head Neck Surg. 105:457-463, 1991.

SEIDMAN MD, SHIVAPUJA BG. The protective effects of allopurinol and superoxide dismutase on noise-induced cochlear damage. Otolaryngol. Head Neck Surg. 109:1052-1056, 1993.

Shone G, Raphael Y, Miller JM. Hereditary deafness occurring in cd/ 1 mice. Hear. Res. 57:153-156, 1991.

Sies H, Sharov VS, KLotz L-O, Briviba K Glutathione peroxidase protects against peroxynitrite-mediated oxidations. J. Biol. Chem. 272:27812-27817, 1997.

Spector A, KusJak JR, Ma W, WANG RR, Ho Y-S, YANG Y. The effect of photochemical stress upon the lenses of normal and glutathione peroxidase-1 knockout mice. Exp. Eye Res. 67:457471, 1998, DOI:10.1006/ exer.1998.0548.

Weisbrot-Lefkowitz M, Reuhl K, Perry B, Chan PK, Inouye M, MIROCHNITCHENKO O. O verexpression of human glutathione peroxidase protects transgenic mice against focal cerebral ischemia/ 
reperfusion damage. Mol. Brain Res. 53:333-338, 1998, DOI: 10.1016/ S0169-328X, (97), 00313-6.

WILLOTT JF. Aging and the Auditory System: Anatomy, Physiology, and Psychophysics. Singular Publishing Group, San Diego 1991.

Yamane H, Nakal Y, Takayama M, Iguch H, Nakagawa T, Kojima $K$. Appearance of free radicals in the guinea pig inner ear after noise-induced acoustic trauma. Eur. Arch. Otorhinolaryngol. 252:504-508, 1995.

Yamasoba T, Nuttall AL, Harris C, Raphael Y, Miller JM. Role of glutathione in protection against noise-induced hearing loss. Brain Res. 784:82-90, 1998, DOI:10.1016/ S0006-8993, (97), 01156-6.

Yoshida N, Hequembourg SJ, Atencio CA, Rosowski JJ, Liberman
MC. Acoustic injury in mice:129/ SvEv is exceptionally resistant to noise-induced hearing loss. Hear. Res. 141:97-106, 2000, DOI:10.1016/ S0378-5955, (99), 00210-5.

YOSHIDA N, KRISTIANSEN A, LIBERMAN MC. H eat stressand protection from permanent acoustic injury in mice. J. Neurosci. 19:1011610124, 1999.

Yoshida T, Maulik N, Engelman RM, Ho Y-S, Magnenat J-L, Rousou JA, FLACK JE, Deaton D, DAS DK. Glutathione peroxidase knockout mice are susceptible to myocardial ischemia reperfusion injury. Circulation. 96:216-220, 1997.

ZHENG QY, JOHNSON KH, ERWAY LC. Assessment of hearing in 80 inbred strains of mice by ABR threshold analysis. Hear. Res. 130:94-107, 1999, DOI:10.1016/ S0378-5955, (99), 00003-9. 